\title{
3-D finite-difference simulation of seismic fault zone waves-Application to the fault zone structure of the Mozumi-Sukenobu fault, central Japan-
}

\author{
Yutaka Mamada $^{1}$, Yasuto Kuwahara ${ }^{1}$, Hisao Ito ${ }^{1}$, and Hiroshi Takenaka ${ }^{2}$ \\ ${ }^{1}$ Geological Survey of Japan, National Institute of Advanced Industrial Science and Technology, AIST Tsukuba Central 7, \\ 1-1, Higashi 1-Chome, Tsukuba-shi, Ibaraki 305-8567, Japan \\ ${ }^{2}$ Department of Earth and Planetary Sciences, Kyushu University, Hakozaki 6-10-1, Fukuoka 812-8581, Japan
}

(Received January 4, 2002; Revised August 9, 2002; Accepted August 9, 2002)

\begin{abstract}
Fault zone waves have the potential to be a powerful tool to reveal the fine structure of a fault zone down to the seismogenic depth. Seismic fault zone waves include head waves, trapped waves and direct body waves propagating in the fault zone. 3-D numerical simulation is necessary to interpret the waveforms in the presence of low-velocity zones with relatively complex fault structure. We computed finite difference (FD) synthetic seismograms to fit the seismograms of explosions, which contain frequencies up to $25 \mathrm{~Hz}$, recorded by a linear seismometer array across the Mozumi-Sukenobu fault, central Japan. We find fault zone head waves, direct $P$ waves propagating within the low-velocity zone and wave trains following the direct $P$ waves associated with the fault for both observed and synthetic waveforms. Thus, modelling of fault zone waves is expected to determine details of complex fault zone structure.
\end{abstract}

\section{Introduction}

Fault-zone structures are thought to have reduced seismic velocities because rocks within fault zones have suffered more damage than the surrounding rocks. The lowvelocity zone can act as a waveguide for seismic fault zone head and trapped waves. Fault-zone head waves propagate along material discontinuity interfaces, and trapped waves are critically reflected phases travelling inside low velocity zone (Ben-Zion and Aki, 1990; Ben-Zion, 1998). Seismic fault zone waves have been observed above several major faults (e.g., Ito and Kuwahara, 1996; Li et al., 1999; Ito et $a l ., 2002)$ and are being used to determine fault structures with a resolution of a few tens of meters (e.g., Li et al., 1998, 2000, 2002).

In addition to these analyses, Ben-Zion (1989, 1990, 1999) and Ben-Zion and Aki (1990) have developed 2-D and 3-D analytical solutions for seismic wavefields generated by double-couple sources at material discontinuities in planeparallel structures. These results are a powerful tool for obtaining an accurate solution for a simple fault zone model. Several observations suggest that real fault zones have complex structure, for example, fault segmentation (e.g., Aki, 1984; Li et al., 1994; Ito et al., 1998). To determine such complex structure, a numerical simulation to calculate the seismic wavefield for irregular 3-D models is necessary (e.g., Graves, 1996; Igel et al., 2002).

Currently the modelling of fault zone structure using 3-D finite difference (FD) simulation is being performed ( $\mathrm{Li}$ et al., 1999, 2000). In these studies, the waves arriving after $S$ waves containing a low frequency component below $5 \mathrm{~Hz}$

Copy right(c) The Society of Geomagnetism and Earth, Planetary and Space Sciences (SGEPSS); The Seismological Society of Japan; The Volcanological Society of Japan; The Geodetic Society of Japan; The Japanese Society for Planetary Sciences. has been used. In this study, we focused on the waves generated by four explosive sources detonated on the MozumiSukenobu fault, central Japan (Ito et al., 2001). Fault zone trapped waves from natural earthquakes with a dominant frequency of $10 \mathrm{~Hz}$ were observed and modelled to obtain $30 \mathrm{~m}$ low-velocity zone (Ito et al., 2002). In contrast, waves generated by the explosions are primarily $P$ waves and contain high frequencies up to $30 \mathrm{~Hz}$. These high frequency waves have the potential to reveal more detailed structures of fault zones than the previous studies. We focused on numerical solutions for 3-D elastic wave propagation through fault zone structure. Our goal is to fit the synthetic seismograms to the seismograms recorded by a linear seismometer array across the Mozumi-Sukenobu fault with explosive sources.

\section{Numerical Method}

To obtain the solution of the 3-D elastic wave equation, we applied a staggered-grid finite-difference method to the velocity-stress formation of the elastodynamic equation. We used a fourth- and second-order approximation for the spatial and time derivatives, respectively, which has been described in other studies (Virieux, 1984; Levander, 1988; Hayashida et al., 1999). The staggered-grid was defined on a 3-D Cartesian coordinate system mentioned below. A representation of source was included in the staggered-grid system using the stress components (e.g., Coutant et al., 1995). The source time function was given by

$$
s(t)=\left\{1-\cos \left(2 \pi t / T_{0}\right)\right\} / T_{0} \quad\left(0 \leqq t \leqq T_{0}\right) .
$$

Here $T_{0}$ represents the pulse width of the source time function. In our formulation, we used a free surface boundary condition for the earth's surface and an absorption boundary condition for the other boundaries. We used the absorption 
boundary condition of Clayton and Engquist (1977), as applied to the velocity components of the wave field, which has maximum absorbancy for normally incident plane waves in the outgoing wave field. In addition to this boundary condition, we adopted another absorption boundary condition introduced by Cerjan et al. (1985), which attenuates the reflected waves by multiplying the factor

$$
G i=\exp \left\{-[A(N-i)]^{2}\right\} \quad(1 \leqq i \leqq N)
$$

by the velocity and stress field at the grid points located within $N$ points from the model boundary at each time calculation step. Here $i$ represents the grid position relative to the nearest model boundary. In our model, we set $A=0.015$ and $N=20$. Our code has been tested through comparisons with analytical solutions obtained by the reflectivity method (Pitarka, 1999) for two velocity models (homogeneous halfspace and two-layered models with a strong velocity contrast). The agreement between both techniques was as good as those in recent FD studies using a staggered grid (e.g., Coutant et al., 1995; Graves, 1996; Pitarka, 1999), suggesting that our code can handle models with strong velocity contrasts such as fault zones.

\section{Seismic Array Observation across the Fault}

Ito et al. (2001) observed fault-zone trapped waves generated by near-surface explosions within and outside the fault zone of Mozumi-Sukenobu fault, using a linear seismic array to measure the structure of the fault. They detonated explosions at four sites S1, S2, S3 and S4 (Fig. 1). A linear seismic array was deployed across the Mozumi-Sukenobu fault trace at a depth of $300 \mathrm{~m}$ in the underground research tunnel. The length of the array is roughly $500 \mathrm{~m}$ long with a seismometer spacing of about $15 \mathrm{~m}$ and 32 seismometers. Each station recorded three-component seismograms. Sites S1 and S3 were considered to be located within the MozumiSukenobu fault zone at distances of 2 and $4 \mathrm{~km}$ northeast of
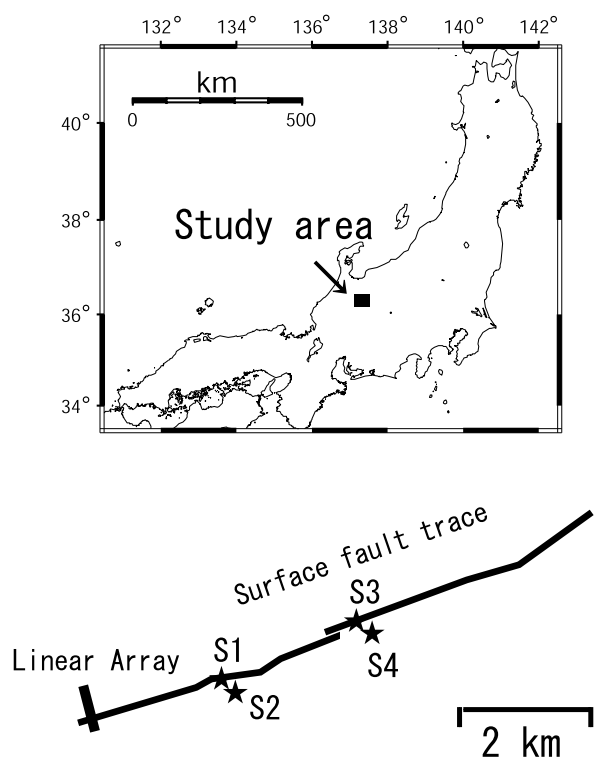

Fig. 1. The map of study area, and the schematic illustration of linear seismometer array and four explosions (S1, S2, S3 and S4) relative to surface trace of the Mozumi-Sukenobu fault. The linear array consists of 32 three-component velocity-type (L22-E, MarkProducts) seismometers. the seismic array. Sites S2 and S4 were located about $100 \mathrm{~m}$ south of the fault zone at distances of about 2 and $4 \mathrm{~km}$ northeast of the seismic array.

Figures 2(a) to (d) show seismograms recorded at the cross-fault array for explosions at S1 to S4, respectively. Here we show only the fault zone-parallel component in which remarkable phases can be clearly seen. All seismograms shown here are low-pass filtered at $25 \mathrm{~Hz}$. For explosions S3 and S4, we have some difficulties fitting the simulation results to the real seismograms for the simple lowvelocity zone model inferred from the seismograms for explosions S1 and S2. This may be related to the complexities of fault zone structure, for example, offset of surface traces of the fault between source point S3 and the station array, as

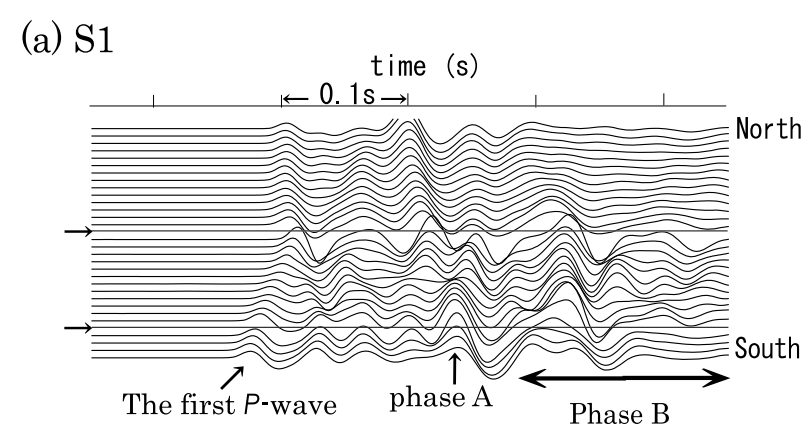

(b) $\mathrm{S} 2$

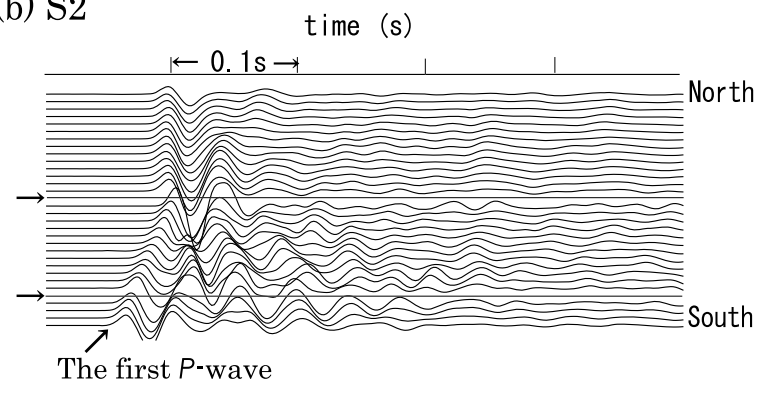

(c) $\mathrm{S} 3$

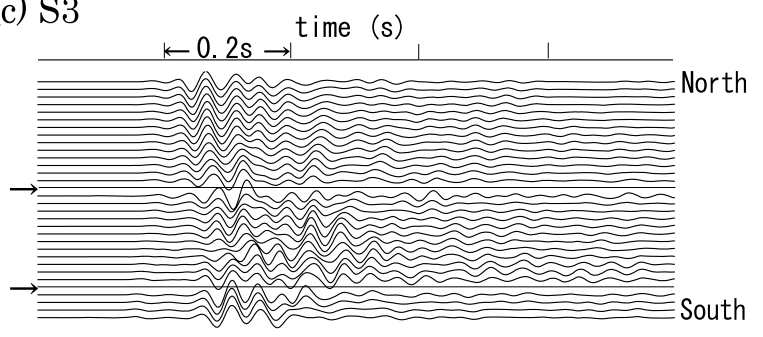

(d) $\mathrm{S} 4$

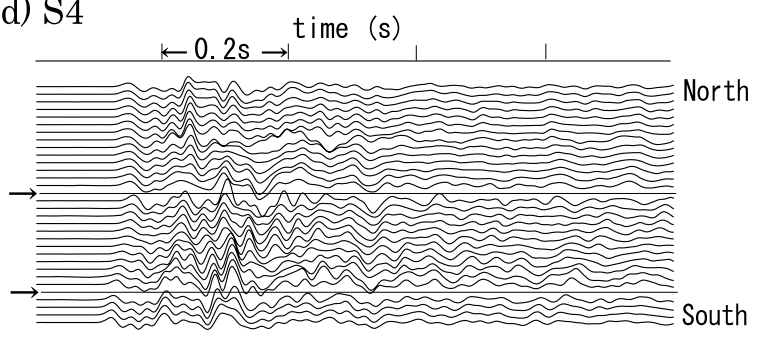

Fig. 2. Fault zone parallel component of observed seismograms. The panels from top to bottom represent $25 \mathrm{~Hz}$ low-pass filtered seismograms for the explosions S1 to S4. Each trace for S1 to S4 is normalized by the constant value defined for each panel. The horizontal arrows show the boundary between low-velocity zone and host rock. The traces are aligned from north (top) to south (bottom) for each explosion. 
can be seen in Fig. 1. Thus we discuss only the results of explosions $\mathrm{S} 1$ and $\mathrm{S} 2$ below. We notice that there is a time delay of the first $P$-wave arrival in the center of the fault zone in Fig. 2(a). We use this apparent velocity to estimate the $P$ wave velocity within the low-velocity zone interpreting this phase as a fault zone head wave.

Distinctive phases with large amplitudes appear about $0.15 \mathrm{~s}$ after the first arrival, especially at the station located within the fault zone for S1. These phases are labelled phase A in Fig. 2(a). Following this phase, large-amplitude wave trains labelled phase B can be clearly seen on the stations in the low-velocity zone. Similar phases such as the first arrival and phases A and B have also been observed at the surface stations adjacent to the southern Joshua Tree earthquake rupture zone (Hough et al., 1994). Figure 2(b) shows the seismograms for source S2 outside the fault zone. In contrast to Fig. 2(a), much less complexity is seen.

\section{Results of Simulation}

We show synthetic seismograms to compare the observations for the explosive sources at S1 (Fig. 3(a)) and S2 (Fig. 3(b)). In the simulations, the number of grids is 260 , 100 and 60 in $x, y$ and $z$ directions, respectively. Here the $x$ and $y$ axes are parallel and perpendicular to the fault trace, and the $z$ axis is in depth. The grid spacing is $20 \mathrm{~m}$ in all directions. The time step of the calculation is $0.001 \mathrm{~s}$. The source time function was given by Eq. (1) with $T_{0}=0.05 \mathrm{~s}$.
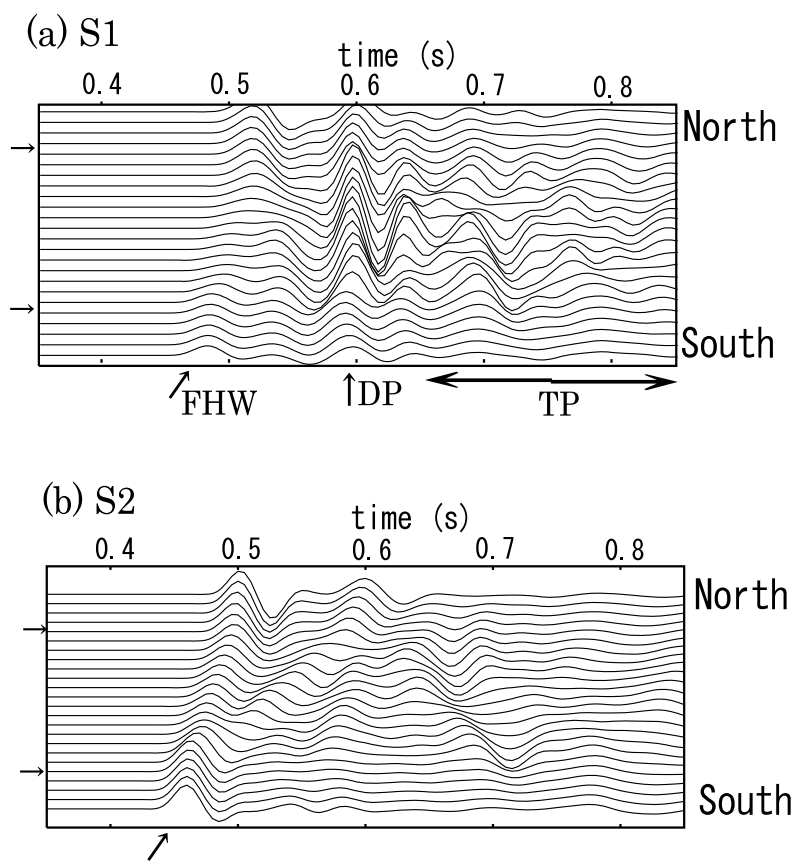

Fig. 3. Fault zone parallel component of calculated seismograms. A linear seismometer array is placed at the depth of $300 \mathrm{~m}$ across the low-velocity zone. The station spacing is $20 \mathrm{~m}$. The top and bottom panels are results of the calculations for S1 and S2, respectively. All traces in each panel are normalized by the constant value defined for each panel. The time is measured from the shot time for both panels. The approximate locations of the phases of fault zone head waves, trapped waves and direct $P$-waves identified in Fig. 4 on seismograms are marked by arrows with labels FHW, TP and DP, respectively. The horizontal arrows show the boundary between the low velocity zone and host rocks. The traces are aligned from north (top) to south (bottom) for each case.
The source used in these calculations is an isotropic explosion. The sources were placed at a depth of $60 \mathrm{~m}$ from the earth's surface, matching the actual depths.

We adopted a $200 \mathrm{~m}$-wide uniform low-velocity zone and a velocity reduction of fault zone $S$ waves by $40 \%$ from the velocity of the surrounding rock $(2.7 \mathrm{~km} / \mathrm{s})$ referring to the results of Ito et al. (2002). We used a $P$-wave velocity of $V p=4.6 \mathrm{~km} / \mathrm{s}$ from the travel time of the first $P$ wave outside the low-velocity zone. For the estimation of the $P$-wave velocity within the low-velocity zone, the apparent velocity of first arrivals were used as mentioned above, and we obtained $V p=3.6 \mathrm{~km} / \mathrm{s}$. However the velocity of the surrounding rocks to the south of the low-velocity zone is probably higher than to the north because the apparent velocity from the center station in the low-velocity zone to the southern station is lower than that to northern station. We then assumed that the $V p=4.3 \mathrm{~km} / \mathrm{s}$ and $V s=2.4 \mathrm{~km} / \mathrm{s}$ outside the low-velocity zone in northern part.

Figure 3(a) shows synthetic seismograms for S1 in which the source is within the low-velocity zone. We can identify three major phases; the fault zone head waves at the first arrival (labeled FHW), the distinctive phase with a large amplitude following the head waves (labeled DP) and then wave trains of trapped waves with a relatively large amplitude (labeled TP). Figure 3(b) shows the seismograms for S2 with the source located outside the low-velocity zone. We can see neither the distinctive phase after the first arrival nor wave trains within the low-velocity zone, unlike the seismograms for S1. Comparing observed seismograms in Figs. 2(a), (b) with synthetic ones Figs. 3(a), (b), the overall properties of both waveforms match. We will compare these carefully in the next section.

\section{Discussion and Summary}

In order to identify the phase A, we showed the synthetic seismograms for S1 obtained at stations that are placed at the depth of $300 \mathrm{~m}$ in the center of low-velocity zone at distances of $200 \mathrm{~m}$ to $2200 \mathrm{~m}$. We find two clear phases in Fig. 4 which are identical with the phases labelled FHW and DP in Fig. 3(a). The apparent velocities of FHW and DP are almost the same as the velocities of the $P$ wave in the host rock on the south side and the $P$ wave in the low-velocity

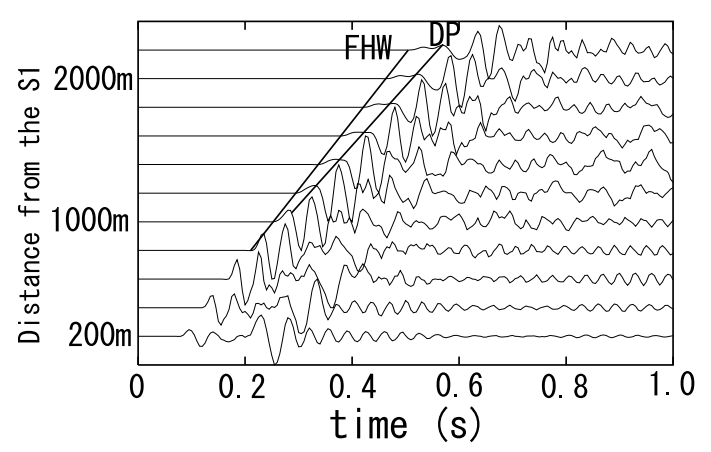

Fig. 4. Record section of synthetic seismograms. The distance from the explosion point is shown in the vertical axis. The arrivals of two clear phases FHW and DP are represented in the figure. The apparent velocity of DP is $3.6 \mathrm{~km} / \mathrm{s}$, and this velocity is consistent with the $P$-wave velocity in the low-velocity zone. 
zone, respectively. Therefore the DP phase is the direct $P$ wave propagating within the low-velocity zone. The time difference between the first $P$ wave and the phase A on the observed seismograms is almost equal to that between the phases FHW and DP in synthetic seismograms. We can then identify phase $\mathrm{A}$ as the direct $P$ wave propagating within the low-velocity zone.

Next we compare in detail the observed and synthetic seismograms. For the explosion S1, the fault zone head wave, the direct $P$ wave and trapped waves on the observed seismograms are identified in the simulated ones. From the simulation, we identified the large phase (phase A) $0.15 \mathrm{~s}$ after the first arrival in the observed seismograms as the direct $P$ wave propagating within the low-velocity zone. For the explosion S2, the observed seismograms have the properties that the most remarkable phase is the first $P$-wave and the waveforms are much simpler than those for S1. These aspects are consistent with those of the synthetic waveforms. Thus, the overall properties are well simulated by the numerical calculations for the S1 and S2 explosions. However, we find the difference that the wave energy following the first arrival on the observed seismograms is relatively large in the south part of fault zone compared to the synthetics for S2. A discrepancy in the direct $P$ wave in observed and simulated seismograms for $\mathrm{S} 1$ can also be seen: the direct $P$ waves within the low-velocity zone are almost in phase across the array in the simulation, but phase shifts of the waves occur within the zone on the observed seismograms. These discrepancies suggest that the low-velocity zone has more complex structure than the present model.

In summary, the general properties of the observed fault zone waves are consistent with the simulation for remarkably high frequency waveforms, up to $25 \mathrm{~Hz}$. However, consideration of more complex structures is necessary to interpret the observed waveform in detail.

Acknowledgments. Discussions with Yong-Gang Li, Kin'ya Nishigami and Takashi Mizuno were very helpful in interpreting the seismograms. The reviewer John E. Vidale, an anonymous reviewer and guest editor for the special issue Gregory C. Beroza provided valuable suggestions to improve the manuscript.

\section{References}

Aki, K., Asperities, barriers, characteristic earthquakes and strong motion prediction, J. Geophys. Res., 89, 5867-5872, 1984.

Ben-Zion, Y., The response of two joined quarter spaces to SH line sources located at the material discontinuity interface, Geophys. J. Int., 98, 213 222, 1989

Ben-Zion, Y., The response of two half space to point dislocations at the material interface, Geophys. J. Int., 101, 507-528, 1990.

Ben-Zion, Y., Properties of seismic fault zone waves and their utility for imaging low velocity structures, J. Geophys. Res., 103, 12567-12585, 1998.

Ben-Zion, Y., Corrigendum: The response of two half spaces to poin dislocations at the material interface by Ben-Zion (1990), Geophys. J.
Int., 137, 580-582, 1999

Ben-Zion, Y. and K. Aki, Seismic radiation from an SH line source in a laterally heterogeneous planar fault zone, Bull. Seism. Soc. Am., 80, 971994, 1990.

Cerjan, C., D. Kosloff, R. Kosloff, and M. Reshef, A nonreflecting boundary condition for discrete acoustic and elastic wave equations, Geophysics, 50, 705-708, 1985 .

Clayton, R. and B. Engquist, Absorbing boundary conditions for acoustic and elastic wave equations, Bull. Seism. Soc. Am., 67, 1529-1540, 1977.

Coutant, O., J. Virieux and A. Zollo, Numerical source implementation in a 2D finite difference scheme for wave propagation, Bull. Seism. Soc. Am., 85, 1507-1512, 1995

Graves, R. W., Simulating seismic wave propagation in 3D elastic media using staggered-grid finite differences, Bull. Seism. Soc. Am., 86, 1091$1106,1996$.

Hayashida, T., H. Takenaka, and T. Okamoto, Development of 2D and 3D codes of the velocity-stress staggered-grid finite-difference method for modeling seismic wave propagation, Sci. Repts., Dept. Earth and Planet Sci., Kyushu Univ., 20, 99-110, 1999 (in Japanese with English abstract). Hough, S. E., Y. Ben-Zion, and P. Leary, Fault-zone waves observed at the southern Joshua Tree earthquake rupture zone, Bull. Seism. Soc. Am., 84 761-767, 1994.

Igel, H., G. Jahnke, and Y. Ben-Zion, Numerical simulation of fault zone guided waves: accuracy and 3-D effects, Pageoph, 159, 2067-2083, 2002.

Ito, H. and Y. Kuwahara, Trapped waves along the Nojima fault from the aftershock of Kobe earthquake, 1995, Proceedings of VIIIth International Symposium on the observation of the Continental Crust Through Drilling, 399-402, 1996.

Ito, H., K. Nishigami, and Y. Kuwahara, Trapped wave analysis - fault segmentation and deep structure-, Chikyu Monthly, 20, 154-159, 1998 (in Japanese).

Ito, H., Y. Kuwahara, K. Imanishi, T. Kiguchi, K. Nishigami, T. Mizuno, Hasbaator, and A. Takeuchi, Fine structure of the Mozumi-Sukenobu fault deduced by explosions, Program abstract of Seism. Soc. Jpn. Meeting, 2001 (in Japanese).

Ito, H., K. Nishigami, and Y. Kuwahara, Fault guided waves and their implications for the width of deep extension of the Mozumi-Sukenobu faults, central Japan, Geophys. Res. Lett., 2002 (in preparation).

Levander, A. R., Fourth-order finite-difference P-SV seismograms, Geophysics, 53, 1425-1436, 1988

Li, Y. G., J. E. Vidale, K. Aki, C. J. Marone, and W. H. K. Lee, Fine structure of the Landers fault zone: segmentation and the rupture process, Science, 265, 367-369, 1994.

Li, Y. G., K. Aki, J. E. Vidale, and M. G. Alvarez, A delineation of the Nojima fault ruptured in the M7.2 Kobe, Japan earthquake of 1995 using fault zone trapped waves, J. Geophys. Res., 103, 7247-7263, 1998.

Li, Y. G., K. Aki, J. E. Vidale, and F. Xu, Shallow structure of the Landers fault zone from explosion-generated trapped waves, J. Geophys. Res. 104, 20257-20275, 1999

Li, Y. G., J. E. Vidale, K. Aki, and F. Xu, Depth-dependent structure of the Landers fault zone from trapped waves generated by aftershocks, $J$. Geophys. Res., 105, 6237-6254, 2000.

Li, Y. G., J. E. Vidale, S. M. Day, D. D. Oglesby, and the SCEC Field Working Team, Study of the 1999 M7.1 Hector Mine, California earthquake fault plane by trapped waves, Bull. Seism. Soc. Am., 92, 13181332, 2002.

Pitarka, A., 3D finite-difference modeling of seismic motion using staggered grids with nonuniform spacing, Bull. Seism. Soc. Am., 89, 54-68, 1999.

Virieux, J., SH-wave propagation in media: Velocity-stress finite-difference method, Geophysics, 49, 1933-1957, 1984.

Y. Mamada (e-mail: y-mamada@aist.go.jp), Y. Kuwahara, H. Ito, and H. Takenaka 